\title{
Ligand supported facile conversion of uranyl(VI) to uranium(IV) in organic and aqueous media
}

\author{
Radmila Faizova, ${ }^{a}$ Farzaneh Fadaei-Tirani, ${ }^{a}$ Rizlan Bernier-Latmani ${ }^{\mathrm{b}}$ and Marinella Mazzanti ${ }^{\star a}$
}

\begin{abstract}
Reduction of uranyl(VI) to $\mathrm{U}(\mathrm{V})$ and to $\mathrm{U}(\mathrm{IV})$ is important in uranium environmental migration and remediation processes. Here we report the anaerobic reduction of a uranyl $\mathrm{U}(\mathrm{VI})$ complex supported by a picolinate ligand in both organic and aqueous media. We show that the $\left[\mathrm{U}^{\mathrm{V}} \mathrm{O}_{2}\right.$ (dpaea)] complex is readily converted to the cis-boroxide $\mathrm{U}(\mathrm{IV})$ species via diborane-mediated reductive functionalization in organic media. Remarkably, in aqueous media the uranyl(VI) complex is rapidly converted, by $\mathrm{Na}_{2} \mathrm{~S}_{2} \mathrm{O}_{4}$, a reductant relevant for chemical remediation processes, into the stable uranyl( $(\mathrm{V})$ analogue, which is then slowly reduced to yield a water insoluble trinuclear U(IV) oxo-hydroxo cluster. This report provides the first example of direct conversion of a uranyl(VI) compound to a well-defined molecular U(IV) species in aqueous conditions.
\end{abstract}

Uranyl(VI) species $\left(\mathrm{UO}_{2}{ }^{2+}\right.$ are highly stable and highly soluble in aqueous solutions which results in a problematic high mobility in contaminated environment where they are the predominant form of uranium. ${ }^{[1]}$ Efforts to mitigate the migration of uranium in the environment have focused on the anaerobic microbially and chemically-mediated reduction of $\mathrm{UO}_{2}{ }^{2+}$ to insoluble U(IV) phases, ${ }^{[2]}$ a process that is thought to involve a $\mathrm{U}(\mathrm{V})$ intermediate. ${ }^{[3]}$ The reduction process is also affected by the presence of complexing inorganic or organic ligands such as carboxylates resulting in the formation of unidentified soluble U(IV) species. ${ }^{[4]}$

The need for a better understanding of the mechanism of the environmental reduction of uranyl(VI) to uranium(IV), which is key for the development of remediation strategies, has spurred numerous studies of the reduction and functionalization of uranyl species both in gas phase ${ }^{[5]}$ and in non-aqueous anaerobic media. ${ }^{[1 a, 1 b, 6]}$ Significant progress has been made in recent years in the development of systems that allowed the reduction of uranyl(VI) to uranyl(V). ${ }^{[1 a]}$ In contrast fewer examples of controlled reduction of uranyl $(\mathrm{VI})$ and uranyl $(\mathrm{V})$ complexes to well defined U(IV) compounds have been reported and they all require the preliminary functionalization of the two uranyl oxo ligands with Lewis acids ${ }^{[1 a, 6 b]}[6 a, 7]$ or metal cations. ${ }^{[8]}$

However, the low stability in aqueous media of the reported uranyl( $(\mathrm{V})$ systems both with respect to ligand dissociation and proton induced disproportionation ${ }^{[9]}$ renders impossible their use in the study of uranyl reduction under environmentally relevant conditions, i. e. in aqueous media.

Recently, we reported ${ }^{[10]}$ the synthesis and the structure of the uranyl $(\mathrm{V})$ complex $\left[\mathrm{K}(2.2 .2\right.$. cryptand) $]\left[\mathrm{UO}_{2}\right.$ (dpaea)], 2 (dpaea ${ }^{2-}$ (bis(pyridyl-6-methyl-2-carboxylate)-ethylamine) which was

[a] Institute of Chemical Sciences and Engineering, Swiss Federal Institute of Technology Lausanne (EPFL), CH-1015 Lausanne, Switzerland

E-mail: marinella.mazzanti@epfl.ch.

[b] School of Architecture, Civil and Environmental Engineering, EPFL, $\mathrm{CH}-1015$ Lausanne, Switzerland

Supporting information for this article and ORCID identification number(s) for the author(s) is given via a link at the end of the document. isolated from pyridine. Complex 2 disproportionates in acidic water conditions to yield the $\mathrm{U}(\mathrm{VI})\left[\mathrm{UO}_{2}\right.$ (dpaea)], 1 and $\mathrm{U}(\mathrm{IV})$ $\left[\mathrm{U}(\text { dpaea })_{2}\right]$ complexes, but is stable in water at $\mathrm{pH} 7-11$. The ability of the ligand dpaea ${ }^{2-}$ to stabilize uranyl(V) in organic and aqueous solutions provides access to the study of the reactivity of this species in both media.

Here we report that the uranyl( $\mathrm{VI})$ complex $\left[\mathrm{UO}_{2}(\mathrm{dpaea})\right]$ can be reduced in organic solution to afford a cis-boroxide uranium(IV) species ([U $\mathrm{U}^{\mathrm{V}}$ (dpaea)(OBpin)2(py)], $\mathbf{3}$ via uranyl oxo functionalization. More importantly, we show, for the first time, that reduction of the uranyl(VI), 1, and uranyl(V), 2, complexes can be effected in anaerobic water, without preliminary functionalization of the oxo ligands, to give well-defined molecular U(IV) species, namely the trinuclear $U(I V)$ oxo-hydroxo clusters $\left[\mathrm{Na}\left(\mathrm{H}_{2} \mathrm{O}\right)_{5}\{\mathrm{U}(\text { dpaea })\}_{3}(\mu-\mathrm{O})_{2}(\mu-\mathrm{OH})\left(\mu_{3}-\mathrm{SO}_{3}\right)\right], \quad 4 \quad 4 \quad$ and $[\mathrm{Na}(2.2 .2 \mathrm{crypt})]\left[\{\mathrm{U}(\mathrm{dpaea})\}_{3}(\mu-\mathrm{O})_{2}(\mu-\mathrm{OH})\left(\mu_{3}-\mathrm{SO}_{3}\right)\right]$, 5. We also report the structure of the uranyl(V) $\left[\left\{\mathrm{UO}_{2} \text { (dpaea) }\left(\mathrm{H}_{2} \mathrm{O}\right)\right\}_{2}\{\mu-\right.$ $\left.\left.\left.\mathrm{Na}\left(\mathrm{H}_{2} \mathrm{O}\right)_{4}\right\}\right]\right\}, 6$, complex as obtained from the reduction of $\mathrm{U}(\mathrm{VI})$ with sodium dithionite in water, which is the first example of uranyl( $(\mathrm{V})$ isolated from water.

First the reduction of 1 was explored in organic solution (pyridine). Upon addition of 1 equiv. of diborane pinacolate $\left((\text { Bpin })_{2}\right.$ (pin = pinacolate)) to the uranyl( $\mathrm{VI})$ complex 1 at room temperature, the ${ }^{1} \mathrm{H}$ NMR spectrum of the reaction mixture revealed conversion of the insoluble diamagnetic $\mathrm{U}(\mathrm{VI})$ species to paramagnetic $\mathrm{U}(\mathrm{IV})$ containing species (Fig. S1). Green crystals of ([U'V (dpaea)(OBpin) $\left.)_{2}(\mathrm{py})\right], 3$, suitable for X-ray diffraction studies were obtained in $33 \%$ yield by diffusion of heptane into the pyridine solution.
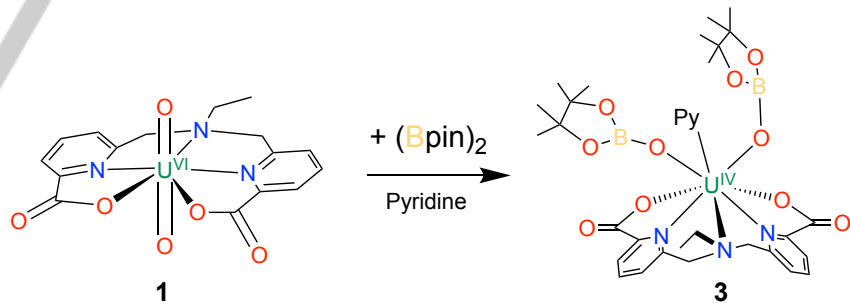

Scheme 1. Synthesis of $\left[U^{I V}(d p a e a)(O B p i n)_{2}(p y)\right](3)$.

The solid-state structure of the complex 3 (Figure 1) shows the presence of a octa-coordinate U(IV) complex where the two trans uranyl( $\mathrm{VI})$ oxo groups of 1 have been converted into two cisboroxide ligands. The conversion involves diborane binding to the uranyl oxo groups and two-electrons transfer through cleavage of the B-B bond. The process is accompanied by a rearrangement of the flexible dpaea ligand from planar to bent which renders possible the switch of the oxo groups for a trans- to cis- position. The ${ }^{1} \mathrm{H}$ NMR spectrum of the reaction mixture shows $50 \%$ conversion of 1 into 3 , but also shows the presence of signals assigned to the pyridine adduct of $\mathrm{OB}(\mathrm{pin})_{2}{ }^{[7 \mathrm{~b}]}$ and of additional paramagnetic signals (Fig. S3). The observed signals suggest that additional U(IV) species are formed that result from reductive oxo abstraction. Oxo-bridged $[\mathrm{O}-\mathrm{U}-\mathrm{O}-\mathrm{U}-\mathrm{O}]^{4+}$ species resulting from reductive oxo abstraction were observed as the only product of the diborane reduction of a macrocylic uranyl(VI) complex recently reported by Love and Arnold. ${ }^{[7 b]}$ 


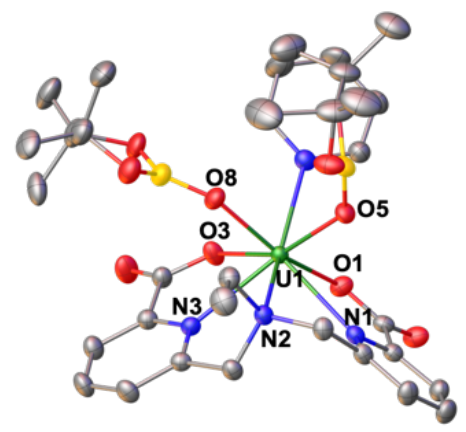

Figure 1. Molecular structure of 3. $\mathrm{H}$ atoms and solvent molecules are removed for clarity. $\mathrm{C}$ grey, $\mathrm{N}$ blue, $\mathrm{O}$ red, $\mathrm{B}$ yellow and $\mathrm{U}$ green

In view of the observed facile reduction of the $\mathrm{U}(\mathrm{VI})$ complex to $\mathrm{U}(\mathrm{IV})$ in pyridine solution and of the high stability of complexes 1 and $\mathbf{2}$ in water we investigated the reduction of uranyl(VI) in water. The reaction of 1 in aqueous media with $\mathrm{AQDSH}_{2}$ (1,8-dihydroxy9,10-anthraquinone-2,7-disulphonic sodium), $\mathrm{NaBH}_{4}$ and $\mathrm{Fe}^{2+}$ did not result in the reduction of the uranyl(VI) complex.

In contrast, the addition of 0.5 equiv. of $\mathrm{Na}_{2} \mathrm{~S}_{2} \mathrm{O}_{4}$ to a yellow suspension of $\left[\mathrm{UO}_{2}\right.$ (dpaea)] in water at $\mathrm{pH}=8.5$ resulted in immediate reaction yielding a pink solution. The ${ }^{1} \mathrm{H}$ NMR spectrum of the reaction mixture, when compared to the spectrum of 2 in $\mathrm{D}_{2} \mathrm{O}$ at $\mathrm{pH} 8.5$, revealed the quantitative conversion of 1 into the uranyl(V) species $\left[\mathrm{UO}_{2} \text { (dpaea) }\right]^{-}$. (Scheme 2; Fig. S4). Crystals of the uranyl(V) complex $\left[\left\{\mathrm{UO}_{2} \text { (dpaea) }\left(\mathrm{H}_{2} \mathrm{O}\right)\right\}_{2}\{\mu-\right.$ $\left.\left.\left.\mathrm{Na}\left(\mathrm{H}_{2} \mathrm{O}\right)_{2}\right\}_{2}\left\{\mathrm{H}_{2} \mathrm{O}\right\}_{2}\right]\right\}$, 6, were obtained by slow evaporation of the $\mathrm{H}_{2} \mathrm{O}$ solution at room temperature (Fig. 2 and Fig. S21). The structure shows a dimer with two anionic $\left\{\mathrm{UO}_{2}(\right.$ dpaea $\left.)\left(\mathrm{H}_{2} \mathrm{O}\right)\right\}$ moieties bridged by two $\mathrm{Na}$ cations binding the carboxylate oxygens. Additionally, two $\mathrm{H}$-bonds $(\mathrm{O} \ldots \mathrm{H}=1.96(6)$ and $2.07(5) \AA)$ are observed between the uranyl( $\mathrm{V})$ oxo group and the water molecules present in the structure.

Moreover, the reduction of $\left[\mathrm{UO}_{2}\right.$ (dpaea)] with 1-2 equiv. of $\mathrm{Na}_{2} \mathrm{~S}_{2} \mathrm{O}_{4}$ in water buffered with $\mathrm{HEPES}$ at $\mathrm{pH}=8.5$ for seven days at room temperature led to the formation of the trinuclear uranium(IV) $\mu$-oxo/hydroxo bridged cluster $\left[\mathrm{Na}\left(\mathrm{H}_{2} \mathrm{O}\right)_{5}\{\mathrm{U}(\mathrm{dpaea})\}_{3}(\mu-\mathrm{O})_{2}(\mu-\mathrm{OH})\left(\mu_{3}-\mathrm{SO}_{3}\right)\right](4)$ that was isolated as a red crystalline solid in up to $68 \%$ yield (obtained using 2 equiv. $\mathrm{Na}_{2} \mathrm{~S}_{2} \mathrm{O}_{4}$ ). XPS analysis of the isolated solid indicated that only U(IV) species are present (Fig. S18).

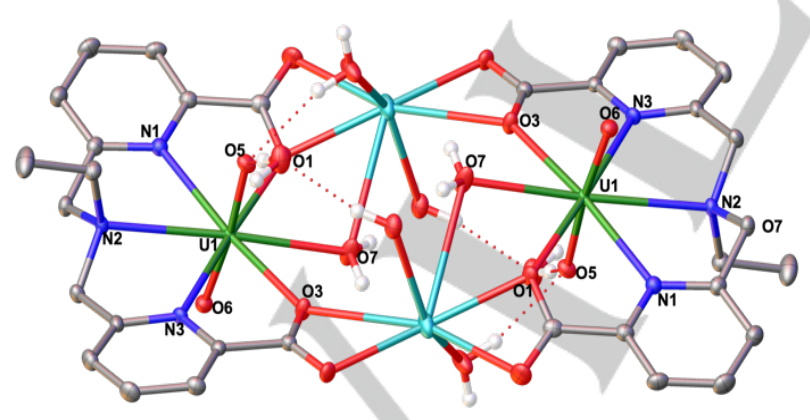

Figure 2. Molecular structure of the $\left[\left\{\mathrm{UO}_{2} \text { (dpaea) }\left(\mathrm{H}_{2} \mathrm{O}\right)\right\}_{2}\left\{\mu \mathrm{Na}\left(\mathrm{H}_{2} \mathrm{O}\right)_{2}\right\}_{2}\left\{\mathrm{H}_{2} \mathrm{O}\right\}_{2}\right]$ complex 6 ( $\mathrm{H}$ atoms of the ligand were removed for clarity) . C grey, $\mathrm{H}$ white, $\mathrm{N}$ blue, $\mathrm{O}$ red and $\mathrm{U}$ green.

Complex 4 could also be isolated by the reduction of the uranyl( $\mathrm{V})$ complex $\left[\mathrm{K}(2.2 .2\right.$.cryptand) $]\left[\mathrm{UO}_{2}\right.$ (dpaea) $]$ with 0.5 equiv. of sodium dithionite in water at $\mathrm{pH} \geq 8$ but with lower yield (up to $40 \%$ ) probably due to the presence of cryptand (Fig. S5).

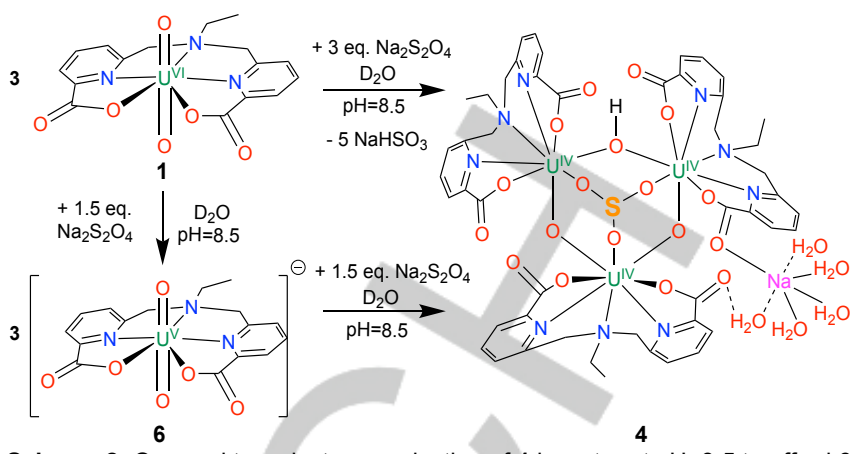

Scheme 2. One and two electrons reduction of 1 in water at $\mathrm{pH}=8.5$ to afford 6 and 4 .

${ }^{1} \mathrm{H}$ NMR studies show that the conversion of $\mathrm{U}(\mathrm{VI})$ to $\mathrm{U}(\mathrm{V})$ is relatively fast (less than 1 hour), but the reduction of the $U(V)$ species to $U$ (IV) is very slow and requires more than seven days to be complete for $15 \mathrm{mM}$ solutions (signals of the $U(V)$ species are still present after seven days as shown in Figures S6 and S7).

Complex 4 is insoluble in water as well as in pyridine, DMSO or $\mathrm{MeCN}$, but can be solubilized in water at $\mathrm{pH}=8$ by the addition of 1 equiv. of 2.2.2.cryptand. The ${ }^{1} \mathrm{H}$ NMR spectrum of the resulting orange solution in $\mathrm{D}_{2} \mathrm{O}($ at $\mathrm{pD}=8$ ) showed signals in the broad range of chemical shifts usually observed for paramagnetic U(IV) species (Fig S9).

Slow evaporation of a water solutions generated by addition of 1 equiv. of 2.2.2.cryptand to 4 allowed to isolated crystals of complex $[\mathrm{Na}(2.2 .2 \mathrm{crypt})]\left[\{\mathrm{U}(\mathrm{dpaea})\}_{3}(\mu-\mathrm{O})_{2}(\mu-\mathrm{OH})\left(\mu_{3}-\mathrm{SO}_{3}\right)\right], 5$.

The ${ }^{1} \mathrm{H}$ NMR spectrum of $\mathbf{5}$ shows the presence of 19 resonances ranging from ca. +45 to $-75 \mathrm{ppm}$ in agreement with the presence of rigid Cs symmetric trinuclear solution species. A diffusion coefficient of $2 \cdot 2 \cdot 10^{-6} \mathrm{~cm}^{2} . \mathrm{s}^{-1}$ and a hydrodynamic radius of $9 \AA$ were calculated, close to the spherical radius estimated from the crystal structure of the complex 5 (8 $\AA$ ) (Table S1).

The FTIR spectrum of the trinuclear complex 4 shows the disappearance of the band assigned to the asymmetric uranyl $\mathrm{O}=\mathrm{U}=\mathrm{O}$ stretch $\left(\mathrm{UO}_{2}{ }^{2+} \approx 790 \mathrm{~cm}^{1} ; \mathrm{UO}_{2}{ }^{+} \approx 920 \mathrm{~cm}^{-1}\right)$ in agreement with the formation of the U(IV)-oxo species (Fig. S12).

The solid-state structure of complex 4 was determined by $\mathrm{X}$-ray diffraction studies (Figure 3 ). The molecular structure of $\mathbf{4}$ shows the presence of a trinuclear cluster with three uranium(IV) cations bridged by two oxide and one hydroxide ligand to yield a sixmembered ring. A sulphite anion also bridges the three $U(I V)$ centres, with a mean $\mathrm{U}-\mathrm{O}_{\text {sulp }}$ distance of 2.35(4) $\AA$, being located at 2.1295(12) $\AA$ above the plane of the three uranium(IV) cations. Each uranium ion is octacoordinated by the dpaea ligand, one $\mathrm{O}_{\text {sulp }}$ and two bridging $\mathrm{O}_{\text {oxo }} / \mathrm{O}_{\text {hydr }}$ atoms. The value of the $\mathrm{U}-\mathrm{O}_{\text {oxo }}$ bond distances ranges from $2.0477(17)$ to $2.1699(17) \AA$ and $U$ Ohydroxo averages at $2.327(3) \AA$ which are both in the range of typical for uranium(IV) oxo and U(IV) hydroxo bond distances. ${ }^{[12]}$ The value of the $\mathrm{U}-\mathrm{O}-\mathrm{U}$ angles in the trimer range from $138.20(9)^{\circ}$ for $\mathrm{U}-\mu-\mathrm{OH}-\mathrm{U}$ to $144.39(9)^{\circ}$ and $148.83(8)^{\circ}(\mathrm{U}-\mu-\mathrm{O}-\mathrm{U})$ and is similar to those found for the only three other trinuclear $U(I V)$ clusters reported so far. ${ }^{[12]} \mathrm{A}$ sodium counter-cation is bound to one of the carboxylate oxygens of the dpaea ligand and its coordination sphere is completed by $5 \mathrm{H}_{2} \mathrm{O}$ molecules.

The molecular structure of $\mathbf{5}$ is presented in Figure $\mathrm{S} 20$ and shows the presence of a structure very similar to that of complex 4.

Removal of the bound sodium counterion does not lead to important changes of the metrical parameters (Table S3).

The clusters $\mathbf{4}$ and $\mathbf{5}$ are the first examples of trinuclear oxo clusters isolated from aqueous media. ${ }^{[12]}$ 


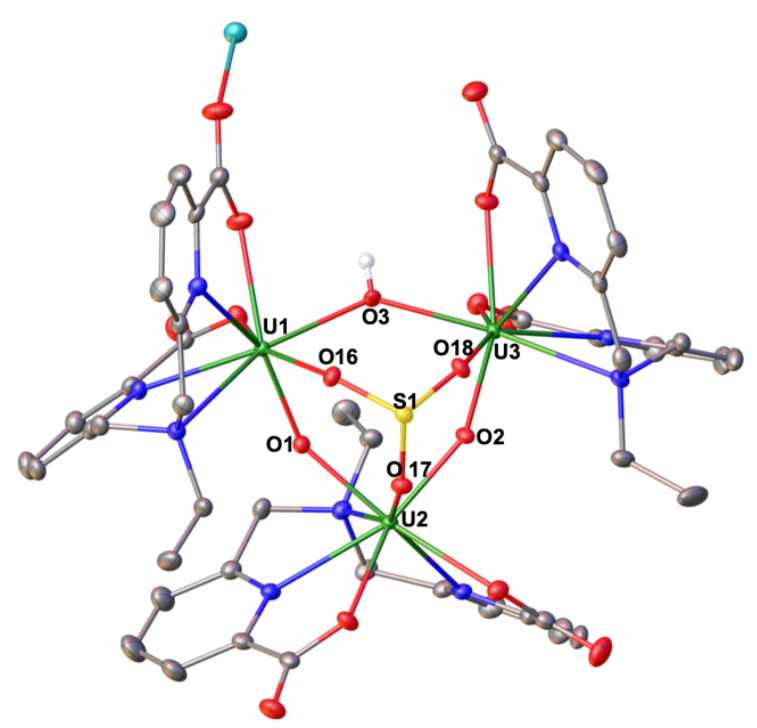

Figure 3. Molecular structure of 4 (ellipsoids are set at $50 \%$ probability). $H$ atoms of the ligand, disorder and solvent molecules and $\mathrm{H}_{2} \mathrm{O}$ coordinated to $\mathrm{Na}^{+}$are removed for clarity. $\mathrm{C}$ grey, $\mathrm{H}$ white, $\mathrm{N}$ blue, $\mathrm{O}$ red, $\mathrm{S}$ yellow, $\mathrm{U}$ green and $\mathrm{Na}$ in light blue.

The stability of complex $\mathbf{5}$ at different $\mathrm{pH}$ conditions was investigated by ${ }^{1} \mathrm{H}$ NMR spectroscopy. The complex was shown to be stable at $\mathrm{pH} 7-9$, while from more acidic solutions $(\mathrm{pH}=5)$ lead to extrusion of the remaining oxo ligands and formation of crystals of the previously reported mononuclear U(IV) complex $\left[\mathrm{U}^{\mathrm{IV}}(\mathrm{dpaea})_{2}\right]$ that has very low solubility in water (Fig. S10).

We also investigated how the reduction of 1 is affected by $\mathrm{pH}$. The reduction of $\left[\mathrm{UO}_{2}\right.$ (dpaea)] with $\mathrm{Na}_{2} \mathrm{~S}_{2} \mathrm{O}_{4}$ cannot be performed in acidic aqueous media ( $\mathrm{pH}$ lower than 7 ) (Fig. S8) because the uranyl(V) $\left[\mathrm{U}^{\vee} \mathrm{O}_{2} \text { (dpaea) }\right]^{-}$complex was found to disproportionate to $\left[\mathrm{U}^{\mathrm{VI}} \mathrm{O}_{2}\right.$ (dpaea)] and [U $\left[\mathrm{U}^{\mathrm{IV}}(\mathrm{dpaea})_{2}\right]$ in these conditions. ${ }^{[10]}$ In contrast, no disproportionation is observed in water solutions of $\left[\mathrm{NaUO}_{2}\right.$ (dpaea)] at $\mathrm{pH} 8$ to 11 , but the reduction of $\mathrm{U}(\mathrm{V})$ to $\mathrm{U}(\mathrm{IV})$ is increasingly slower with increasing of $\mathrm{pH}$. In strongly basic conditions $(\mathrm{pH} \geq 11)$ the uranyl $(\mathrm{V})$ is not reduced by $\mathrm{Na}_{2} \mathrm{~S}_{2} \mathrm{O}_{4}$ in spite of the fact that the reducing power ${ }^{[13]}$ of $\mathrm{Na}_{2} \mathrm{~S}_{2} \mathrm{O}_{4}$ is increased at more basic $\mathrm{pH}$ (Fig S11). This result suggests that the redox properties of $\left[\mathrm{UO}_{2}(\mathrm{dpaea})\right]^{-}$are $\mathrm{pH}$ dependent as previously reported for uranyl(VI) carbonate or phosphate. ${ }^{[14]}$

In view of the ability of the weakly reducing agent $\mathrm{Na}_{2} \mathrm{~S}_{2} \mathrm{O}_{4}$ $\left(\mathrm{E}_{\text {red }}\left(\mathrm{Na}_{2} \mathrm{~S}_{2} \mathrm{O}_{4}\right)=-0.87 \mathrm{~V}\right.$ (vs. $\left.\mathrm{Ag} / \mathrm{AgCl} \mathrm{pH}=7\right)$ to reduce the complexes 1 and 2 to $\mathrm{U}(\mathrm{IV})$ complexes at $\mathrm{pH}=8.5$ we reexamined the previously reported ${ }^{[10]}$ interpretation of the cyclic voltammogram of $\mathbf{2}$ measured in water solution.

The voltammogram of 2 measured in 0.02 M HEPES buffered water solutions $(\mathrm{pH}=7)$ at a glassy carbon working electrode showed the presence of a $\mathrm{U}(\mathrm{V}) / \mathrm{U}(\mathrm{VI})$ oxidation event found at $\mathrm{E}=$ $-0.16-0.00 \mathrm{~V}$ vs $\mathrm{Ag} / \mathrm{AgCl}$. A second redox event was observed at $\mathrm{E}=-1.56--1.65 \mathrm{~V}$ vs $\mathrm{Ag} / \mathrm{AgCl}$ depending on the scan speed. This redox event was also found in the voltammogram of the nonredox active $\mathrm{Zn}^{2+}$ cation [Zn(dpaea)] (Fig. S13) and was assigned to the reduction of the dpaea ligand rather than the $U$ center. At lower scanning speeds a redox event was resolved at $E=-0.6 \mathrm{~V}$ (vs. $\mathrm{Ag} / \mathrm{AgCl})(\mathrm{pH}=7)$ and it was assigned to the $\mathrm{U}(\mathrm{VI}) / \mathrm{U}(\mathrm{V})$ reduction. Cyclic voltammetry experiments were also carried out at $\mathrm{pH}=10$ (Fig. S14) and resulted in a shift of the redox event associated to the $\mathrm{U}(\mathrm{VI}) / \mathrm{U}(\mathrm{V})$ reduction to a more negative potential. This could explain the increased stability of the uranyl(V) species during the reduction with $\mathrm{Na}_{2} \mathrm{~S}_{2} \mathrm{O}_{4}$ at basic $\mathrm{pH}$.

The observed $\mathrm{pH}$ dependency of the reduction of the stable uranyl(V) complex suggest that formation of complex $\mathbf{4}$ is likely to proceed via a proton coupled electron transfer from the reducing agent $\mathrm{Na}_{2} \mathrm{~S}_{2} \mathrm{O}_{4}$. This should result in a cis-bis-hydroxo intermediate that is structurally analogue to the boroxide complex 3 formed in organic solution. A similar proton-coupled electron transfer mechanism was computed for the reduction of uranyl(V) carbonate to U(IV) by $\mathrm{Fe}^{2+}$ in aqueous solution, but it was found to have a high thermodynamic barrier preventing $\mathrm{U}(\mathrm{V}) / \mathrm{U}(\mathrm{IV})$ conversion in the presence of carbonate. ${ }^{[15]}$ Here, the putative bishydroxo $\mathrm{U}(\mathrm{IV})$ intermediate formed from the reduction of $\mathbf{1}$ and $\mathbf{2}$ undergoes condensation due to the basicity of the hydroxo ligand to yield the trinuclear oxo-hydroxo bridged cluster 4 via exclusion of one oxo group as a water molecule. The formation of actinide oxo clusters from condensation reactions is an important process in the water chemistry of actinides that has attracted numerous studies both in organic and water solution due to its relevance in the migration of actinides in the environment. ${ }^{[2 d, 11,16]}$ However, the isolation of well-defined U(IV) oxo clusters from the direct reduction of uranyI(VI) in water is unprecedented. It is of interest to note that even in the presence of the picolinate derivative dpaea water insoluble polynuclear U(IV) species are formed and that the solubility of such species is strongly affected by cation binding. This finding raises the question of whether clusters of this type might form during the homogeneous and heterogeneous reduction of $\mathrm{U}(\mathrm{VI})$ by aqueous sulfide in groundwater, a key process influencing the fate of uranium in the environment.

In conclusion, we have shown that in the presence of polydentate carboxylate ligands it is possible to effect the conversion of $\mathrm{U}(\mathrm{VI})$ to a stable uranyl( $\mathrm{V})$ complex in aqueous media. This uranyl( $\mathrm{V})$ complex can be further reduced to $\mathrm{U}(\mathrm{IV})$ using a reductant $\left(\mathrm{Na}_{2} \mathrm{~S}_{2} \mathrm{O}_{4}\right)$ relevant to chemical remediation. The reduction to $\mathrm{U}(\mathrm{IV})$ is slow but proceeds without the help of oxo functionalization and leads to the formation of a trinuclear oxo cluster via extrusion of one oxo ligand. These findings provide unprecedented insight into the mechanism of abiotic reduction of $\mathrm{UO}_{2}{ }^{2+}$ to $\mathrm{U}(\mathrm{IV})$ in aqueous media rich in organic ligands providing insight into the mechanism and the end-product of $\mathrm{U}(\mathrm{VI})$ reduction in the environment.

\section{Acknowledgements}

We thank E. Solari for elemental analysis, R. Scopelliti for his contribution to structure resolution, P. Mettraux for XPS data collection and M. Molinas for the help with XPS data analysis. This work was supported by the Ecole Polytechnique Fédérale de Lausanne (EPFL) and by the Swiss National Science Foundation grant (number CR23I2_16645).

Keywords: uranium; actinides; cluster compounds; oxo complexes; reduction

[1] aB. E. Cowie, J. M. Purkis, J. Austin, J. B. Love, P. L. Arnold, Chem. Rev 2019, 119, 10595-10637; bS. Fortier, T. W. Hayton, Coord. Chem. Rev. 2010 254, 197-214; cS. A. Cumberland, G. Douglas, K. Grice, J. W. Moreau, EarthSci. Rev. 2016, 159, 160-185.

[2] aD. R. Lovley, E. J. P. Phillips, Y. A. Gorby, E. R. Landa, Nature 1991 350, 413-416; bD. M. Singer, S. M. Chatman, E. S. Ilton, K. M. Rosso, J. F. Banfield, G. A. Waychunas, Environ. Sci. Technol. 2012, 46, 3821-3830; cD. L. Jones, M. B. Andrews, A. N. Swinburne, S. W. Botchway, A. D. Ward, J. R Lloyd, L. S. Natrajan, Chem. Sci. 2015, 6, 5133-5138; dL. S. Natrajan, A. N. Swinburne, M. B. Andrews, S. Randall, S. L. Heath, Coord. Chem. Rev. 2014, 266, 171-193.

[3] J. C. Renshaw, L. J. C. Butchins, F. R. Livens, I. May, J. M. Charnock, J. R. Lloyd, Environ. Sci. Technol. 2005, 39, 5657-5660.

[4] aM. I. Boyanov, K. E. Fletcher, M. J. Kwon, X. Rui, E. J. O'Loughlin, F. E. Loffler, K. M. Kemner, Environ. Sci. Technol. 2011, 45, 8336-8344; bA. J. Francis, C. J. Dodge, Environ. Sci. Technol. 2008, 42, 8277-8282.

[5] aR. J. Abergel, W. A. de Jong, G. J. P. Deblonde, P. D. Dau, I. Captain T. M. Eaton, J. W. Jian, M. J. van Stipclonk, J. Martens, G. Berden, J. Oomens, 
J. K. Gibson, Inorg. Chem. 2017, 56, 12930-12937; bY. Gong, W. A. de Jong, J. K. Gibson, J. Am. Chem. Soc. 2015, 137, 5911-5915.

[6] aJ. J. Kiernicki, M. Zeller, S. C. Bart, Angew. Chem. Int. Ed. Engl. 2017, 56, 1097-1100; bD. D. Schnaars, G. Wu, T. W. Hayton, J. Am. Chem. Soc. 2009, 131, 17532-17533; cJ. J. Kiernicki, D. P. Cladis, P. E. Fanwick, M. Zeller, S. C. Bart, J. Am. Chem. Soc. 2015, 137, 11115-11125.

[7] aJ. L. Brown, C. C. Mokhtarzadeh, J. M. Lever, G. Wu, T. W. Hayton, Inorg. Chem. 2011, 50, 5105-5112; bB. E. Cowie, G. S. Nichol, J. B. Love, P. L. Arnold, Chem. Commun. 2018, 54, 3839-3842; cN. L. Bell, B. Shaw, P. L. Arnold J. B. Love, J. Am. Chem. Soc. 2018, 140, 3378-3384.

[8] aJ. R. Pankhurst, N. L. Bell, M. Zegke, L. N. Platts, C. A. Lamfsus, L. Maron, L. S. Natrajan, S. Sproules, P. L. Arnold, J. B. Love, Chem. Sci. 2017, 8, 108-116; bP. L. Arnold, B. E. Cowie, M. Suvova, M. Zegke, N. Magnani, E. Colineau, J. C. Griveau, R. Caciuffo, J. B. Love, Angew. Chem. Int. Ed. Engl. 2017, 56, 10775-10779.

[9] V. Mougel, P. Horeglad, G. Nocton, J. Pécaut, M. Mazzanti, Chem. Eur. J. 2010, 16, 14365-14377.

[10] R. Faizova, R. Scopelliti, A. S. Chauvin, M. Mazzanti, J. Am. Chem. Soc. 2018, 140, 13554-13557.

[11] K. E. Knope, L. Soderholm, Chem. Rev. 2013, 113, 944-994

[12] aC. T. Palumbo, L. Barluzzi, R. Scopelliti, I. Zivkovic, A. Fabrizio, C Corminboeuf, M. Mazzanti, Chem. Sci. 2019, 10, 8840-8849; bL. Karmazin, M. Mazzanti, J. Pecaut, Inorg. Chem. 2003, 42, 5900-5908; cJ.-C. Berthet, M. Ephritikhine, M. Lance, M. Nierlich, J. Vigner, J. Organomet. Chem. 1993, 460, 47-53.

[13] S. G. Mayhew, Eur. J. Biochem. 1978, 85, 535-547.

[14] aK. Mizuguchi, Y. Y. Park, H. Tomiyasu, Y. Ikeda, J. Nucl. Sci. Technol. 1993 , 30, 542-548; bD. E. Morris, Inorg. Chem 2002, 41, 3542-3547; cE. M. Villa, C. J. Marr, L. J. Jouffret, E. V. Alekseev, W. Depmeier, T. E. AlbrechtSchmitt, Inorg. Chem. 2012, 51, 6548-6558.

[15] M. C. F. Wander, S. Kerisit, K. M. Rosso, M. A. A. Schoonen, J. Phys Chem. A 2006, 110, 9691-9701.

[16] aL. Chatelain, R. Faizova, F. Fadaei-Tirani, J. Pecaut, M. Mazzanti, Angew. Chem. Int. Ed. Engl. 2019, 58, 3021-3026; bL. Soderholm, P. M. Almond, S. Skanthakumar, R. E. Wilson, P. C. Burns, Angew. Chem. Int. Ed. Engl. 2008, 47, 298-302; cS. Hickam, P. C. Burns, in Recent Development in Clusters of Rare Earths and Actinides: Chemistry and Materials, Vol. 173 (Ed.: Z. Zheng), 2017, pp. 121-153. 


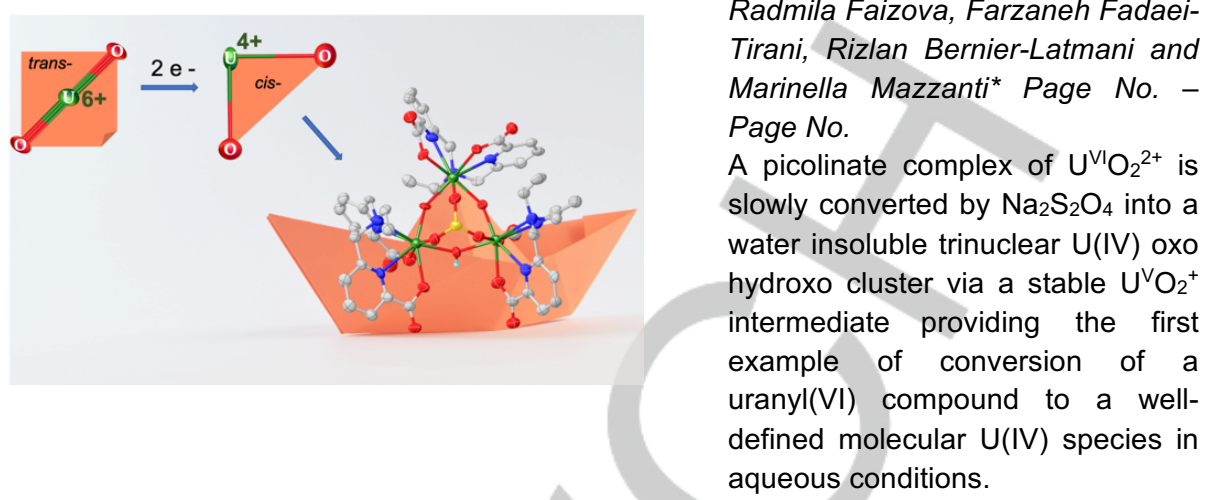

